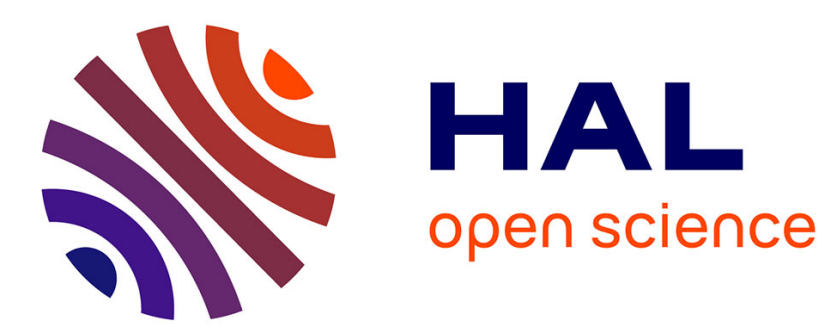

\title{
Embryonic exposure to environmentally relevant concentrations of PCB126 affects prey capture ability of larvae
}

Catherine M. Couillard, Benoît Légaré, Andréane Bernier, Zara Dionne

\section{To cite this version:}

Catherine M. Couillard, Benoît Légaré, Andréane Bernier, Zara Dionne. Embryonic exposure to environmentally relevant concentrations of PCB126 affects prey capture ability of larvae. Marine Environmental Research, 2011, 71 (4), pp.257. 10.1016/j.marenvres.2011.01.010 . hal-00682414

\author{
HAL Id: hal-00682414 \\ https://hal.science/hal-00682414
}

Submitted on 26 Mar 2012

HAL is a multi-disciplinary open access archive for the deposit and dissemination of scientific research documents, whether they are published or not. The documents may come from teaching and research institutions in France or abroad, or from public or private research centers.
L'archive ouverte pluridisciplinaire HAL, est destinée au dépôt et à la diffusion de documents scientifiques de niveau recherche, publiés ou non, émanant des établissements d'enseignement et de recherche français ou étrangers, des laboratoires publics ou privés. 


\section{Accepted Manuscript}

Title: Embryonic exposure to environmentally relevant concentrations of PCB126 affects prey capture ability of Fundulus heteroclitus larvae

Authors: Catherine M. Couillard, Benoît Légaré, Andréane Bernier, Zara Dionne

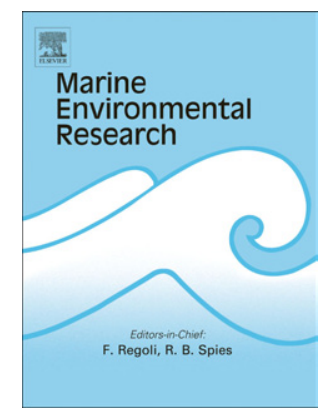

PII: S0141-1136(11)00021-3

DOI: $\quad$ 10.1016/j.marenvres.2011.01.010

Reference: MERE 3506

To appear in: Marine Environmental Research

Received Date: 28 October 2010

Revised Date: 21 January 2011

Accepted Date: 29 January 2011

Please cite this article as: Couillard, C.M., Légaré, B., Bernier, A., Dionne, Z. Embryonic exposure to environmentally relevant concentrations of PCB126 affects prey capture ability of Fundulus heteroclitus larvae, Marine Environmental Research (2011), doi: 10.1016/j.marenvres.2011.01.010

This is a PDF file of an unedited manuscript that has been accepted for publication. As a service to our customers we are providing this early version of the manuscript. The manuscript will undergo copyediting, typesetting, and review of the resulting proof before it is published in its final form. Please note that during the production process errors may be discovered which could affect the content, and all legal disclaimers that apply to the journal pertain. 
Embryonic exposure to environmentally relevant concentrations of PCB126 affects prey capture ability of Fundulus heteroclitus larvae

Catherine M. Couillard ${ }^{1}$, Benoît Légaré ${ }^{1}$, Andréane Bernier ${ }^{2}$, Zara Dionne ${ }^{1}$

${ }^{1}$ Fisheries and Oceans Canada, Maurice Lamontagne Institute, P.O. Box 1000, Mont-Joli, Quebec, Canada G5H $3 Z 4$

${ }^{2}$ Université du Québec à Rimouski, 310 Allée des Ursulines, Rimouski, Quebec, Canada G5L 3A1

*Corresponding author : C.M. Couillard

Phone: (418)775-0681

Fax: (418)775-0718

E-mail address: Catherine.Couillard@dfo-mpo.gc.ca. 


\section{Abstract}

Early life stages from a marine fish species, Fundulus heteroclitus, were exposed to sublethal doses of 3,3',4,4',5-pentachlorobiphenyl (PCB126) to evaluate its effects on ecologically relevant responses: growth and behavior. A few hours after fertilisation, eggs were treated topically with PCB126 (3.1 to 50 pg $\left.\operatorname{egg}^{-1}\right)$. Four days post-hatching (dph), morphological changes (body length and malformations), spontaneous locomotor activity (active swimming speed, rate of travel, \% inactivity), prey capture ability (Artemia franciscana nauplii) and whole body EROD activity were evaluated in larvae. Untreated larvae collected at $0.5,1,2,3,4 \mathrm{dph}$ were also examined. PCB126 did not increase the mortality or malformation rates. Body length and spontaneous locomotor activity were altered only in larvae treated with the highest dose. Treatment with PCB126 caused a dose-responsive reduction in prey capture ability (rate of decline in the number of Artemia) and induction of EROD activity. The lowest observed

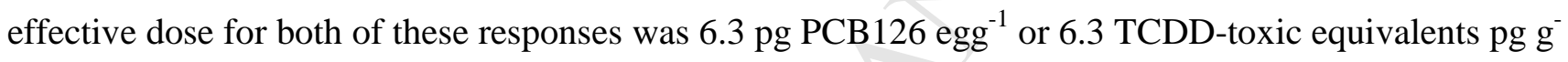
${ }^{1}$ egg, using a TCDD toxic equivalent factor of 0.005 and an egg mass of $5 \mathrm{mg}$. Prey capture efficiency (number of Artemia captured per feeding strike) was reduced at $\geq 12.5 \mathrm{pg} \mathrm{egg}^{-1}$. In untreated developing larvae, prey capture ability and efficiency increased as post-hatching development progressed and EROD activity remained low. The pattern of behavioral responses observed in PCB126-exposed Fundulus larvae differed from that observed in less developed larvae indicating that other mechanisms than retarded development were involved. Behavioral dysfunction was a more sensitive response to PCB126 than morphological alterations and it occurred at environmentally-relevant concentrations.

Keywords: PCB126; fish larvae; Fundulus heteroclitus; behavior; EROD 


\section{Introduction}

Planar halogenated hydrocarbons (PHHs), including coplanar polychlorinated biphenyls (PCBs, and polychlorinated dibenzo- $p$-dioxins and -furans (PCDDs/DFs), are widespread in sediments from industrialized areas and are potentially threatening populations of aquatic organisms. These persistent organic pollutants accumulate in fish tissues and are maternally transferred to the highly vulnerable offsprings. Planar halogenated hydrocarbons interact additively to cause blue sac disease in fish embryos characterized by induction of cytochrome P4501A (CYP1A) enzymes, pericardial and yolk sac edema, hemorrhages, cranio-facial malformations, and impaired growth and survival (Helder, 1981; Guiney et al., 1997). The relative toxic potency of mixtures of PHHs can be predicted on the basis of 2,3,7,8tetrachlorodibenzo- $p$-dioxin (TCDD) toxic equivalency concentrations (TCDD-TEQs), the product of each congener's concentration times its toxic equivalent factor (TEF; the toxicity of each congener relative to TCDD) (Walker and Peterson, 1991). From 1940 to 1980, concentrations of TCDD-TEQs in lake trout (Salvelinus namaycush) from Lake Ontario, Canada, exceeded the lethal toxicity threshold (30 pg TCDD-TEQs $\mathrm{g}^{-1} \mathrm{ww}$ ) and were associated with fry mortality and recruitment failure (Cook et al., 2003). Exposure levels have declined following regulatory actions undertaken in the 1970s, and sublethal effects of PHHs are now a greater concern in lake trout and other fish species.

In mammals, one of the most sensitive responses to PHHs is neurobehavioral disturbances in the offsprings (Hays and Aylward, 2003). The neurobehavioral toxicity of PHHs is poorly known in fish. Impairment of behaviors such as prey capture ability, predation avoidance or swimming in larvae could have a significant impact on recruitment and on fish populations (Weis et al., 2001). In fish larvae, TCDD induces brain damage via Ah-receptor mediated mechanisms. Apoptosis of the neural cells in the dorsal midbrain has been described in zebrafish (Danio rerio) (Dong et al., 2001), medaka (Oryzias latipes) (Cantrell et al., 1998), and mummichog (Fundulus heteroclitus) (Toomey et al., 2001) exposed to TCDD. The primary mechanism of action, described in zebrafish, is induction of CYP1A and oxidative stress in the vascular endothelium accompanied by impaired blood flow and increased albumin permeability in the mesencephalic vein supplying tissues of the dorsal midbrain (Dong et al., 
2002; Tillitt and Papoulias, 2002;Dong et al., 2004). In zebrafish, three of these responses (decrease in blood flow, apoptosis, and increase in albumin permeability) were blocked by antioxidants, cytochrome P450 inhibitors and AhR2 knockdown (Dong et al., 2002;Dong et al., 2004). While several studies have demonstrated the association between TCDD exposure, activation of the AhR and neurological damage, a single study has examined the consequences of these morphological changes for larval survival skills. In swim-up rainbow trout (Oncorhynchus mykiss) hatched from TCDD-injected eggs, biochemical and morphological changes in brain and eyes have been associated with behavioral disturbances: impaired visual/motor functions at $\geq 113 \mathrm{pg}$ of $\mathrm{TCDD} \mathrm{g}^{-1} \mathrm{egg}$ with reduction in prey capture ability at $300 \mathrm{pg}$ of TCDD $\mathrm{g}^{-1}$ egg (Carvalho and Tillitt, 2004). To our knowledge, the behavioral effects of coplanar PCBs have not been investigated in fish although these compounds are powerful developmental neurotoxicants in rats (Piedrafita et al., 2008) and are important contributors to the TCDD-TEQs accumulated in lake trout eggs (Cook et al., 2003).

This paper describes the neurobehavioral toxicity of $3,3^{\prime}, 4,4^{\prime}, 5$ pentachlorobiphenyl (PCB126), a prototypical PHH in early life stages of a model marine fish species, Fundulus heteroclitus, sensitive to PHHs (Toomey et al., 2001;Couillard et al., 2008) and previously used in neurobehavioral assays (Weis et al., 2003). Thresholds for neurobehavioral alterations are compared to those observed for more routinely measured responses: CYP1A induction, malformations and growth impairment. The contribution of retarded development to the behavioral responses observed in PCB126-treated larvae is assessed by comparing these responses to the behavioral changes observed in untreated larvae during post-hatching development.

\section{Materials and Methods}

\subsection{Chemicals}

Ultra Scientific (North Kingstown, RI, USA) supplied the PCB126 (97\% purity). Sigma Chemical (St. Louis, MO, USA) supplied the DMSO (Dimethyl sulfoxide, endotoxin tested, 99\% purity). 


\subsection{Test fish}

Fundulus heteroclitus (200 females and 100 males) were collected in May 2008 from a reference site, Horton's Creek (Miramichi, NB, Canada), and maintained in a 420 L fiberglass tank, with flowing water (salinity $25 \%$ ). To induce gonad maturation, the water temperature was raised progressively from $10^{\circ} \mathrm{C}$ to $19^{\circ} \mathrm{C}$, and a photoperiod of $16 \mathrm{~h}$ light:8 h dark was maintained (Boyd and Simmonds, 1974). Fish were fed pelleted cichlid food (Nutrafin ${ }^{\circledR}$, Rolf C. Hagen, Montreal, QC, Canada) supplemented with dried shrimp and Tubifex worms. Natural spawning was triggered by the introduction of spawning substrates (artificial algae) in the tank containing all the 300 fish. Approximately 5 to $8 \mathrm{~h}$ after natural fertilisation, eggs were collected on spawning substrates and pooled in petri dishes. Eggs were examined with a stereo microscope and normal fertilized eggs (clear, with a regular shape, and with vitelline droplets at one pole) were kept for the toxicity tests.

\subsection{Exposure of embryos to PCB126}

Normal fertilized eggs were randomly divided into 7 groups of 35 eggs. Each egg was treated

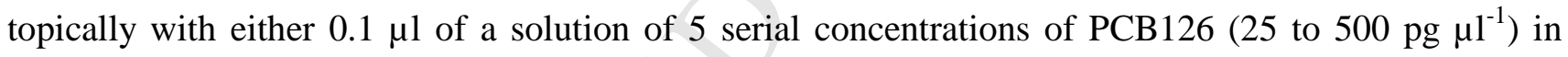
dimethyl sulfoxide (DMSO), with $0.1 \mu \mathrm{DMSO}$ or received no treatment. Topical treatments were applied on the external surface of each egg with a $1 \mu 1$ Hamilton syringe (Helmstetter and Alden, 1995). In a previous study (Couillard et al., 2008), the PCB126 concentration in larvae originating from eggs treated topically with $0.1 \mu 1$ of a 100 pg PCB126 $\mu 1^{-1}$ was $710 \pm 97 \mathrm{pg} \mathrm{g}^{-1}$ wet weight (mean \pm standard deviation).

Following treatment, eggs were randomly distributed and incubated individually in 24-wells clear polystyrene microplates $\left(\operatorname{Costar}^{\circledR} 3526\right.$, Corning Inc. Life Sciences, Lowell, MA, USA) on moist filter papers (Whatman Grade 230, GE Healthcare, Piscataway, NJ, USA) at $22.5^{\circ} \mathrm{C}$ under fluorescent light, and a natural photoperiod of $14 \mathrm{~h}$ light:10 h dark. Hatching was triggered by water immersion, $12 \mathrm{~d}$ after fertilization and both mortality and hatching rates were determined. Shortly after hatching, larvae were transferred individually into $20 \mathrm{ml}$ glass scintillation vials containing $15 \mathrm{ml}$ of saltwater (salinity $25 \%$ ). 
The larvae were kept unfed for $96 \mathrm{~h}$ at $22.5^{\circ} \mathrm{C}$ and under fluorescent light and natural photoperiod, with daily water renewal.

\subsection{Spontaneous locomotor activity analysis}

Four days post-hatching (dph), a subsample of larvae $(\mathrm{N}=10$ per treatment, 35 larvae per plate) was randomly distributed in two 48-wells clear polystyrene microplates (Costar® 3548, working volume 1.0 ml/well, $10.2 \mathrm{~mm}$ well diameter, $18.0 \mathrm{~mm}$ well depth, Corning Inc. Life Sciences, Lowell, MA, USA). Each plate and a video camera (ETC 0385 Dinion XF monochrome camera, Bosch Security Systems, Eindhoven, The Netherlands) were housed inside a Zebrabox ${ }^{\circledR}$ (ViewPoint Life Sciences Inc., Montreal, QC, Canada) that was continuously illuminated with infrared lights. The larvae were left undisturbed for $30 \mathrm{~min}$ in the Zebrabox to acclimate before the video-recording of their locomotor activity during 5 min. Simultaneous tracking of the locomotor activity of all 35 larvae on each microplate was conducted using an automated video-tracking system (Videotrack ${ }^{\circledR}$, ViewPoint Life Sciences Inc.). The locomotor activity was expressed by three variables as described in Alvarez and Fuiman, 2005 (Alvarez and Fuiman, 2005): (1) rate of travel $\left(\mathrm{mm} \mathrm{s}^{-1}\right),(2)$ active swimming speed ( $\left.\mathrm{mm} \mathrm{s}^{-1}\right)$ and (3) inactivity (\% time). The threshold value for minimum pixel change from frame to frame was set to 4 pixels (Emran et al., 2008). Mummichog larvae swim in alternating episodes of swimming and resting. Rate of travel is the average swimming speed $\left(\mathrm{mm} \mathrm{s}^{-1}\right)$ including the resting periods whereas active swimming speed $\left(\mathrm{mm} \mathrm{s}^{-1}\right)$ is the average velocity during active time only. Inactivity is the percentage of time the larva spent resting.

\subsection{Prey capture ability and efficiency}

The prey capture assay was run on a randomly selected subsample of larvae ( $\mathrm{N}=8$ per treatment). The test procedure was modified from a method developed by Gahtan et al. (2005) (Gahtan et al., 2005) to monitor consumption of paramecia by zebrafish. Approximately 20 ( $20 \pm 2$, mean \pm standard deviation) Artemia franciscana nauplii were pipetted in each of 6 contiguous wells filled with saltwater, 
in eight 48-wells microplates. This test was conducted under fluorescent light and at room temperature $\left(22^{\circ} \mathrm{C}\right)$. Six larvae (one larva per treatment, excluding untreated larva) were randomly distributed in each of the Artemia-containing well. Video images of the microplates were recorded with a digital camera (Canon VIXIA HV30 HD Camcorder®, Canon Canada Inc., ONT, Canada) positioned above the microplate during at least $5 \mathrm{~min}$ after the addition of each larva in the plate. Using the images recorded by the video camera, the number of Artemia remaining in each well was counted every $30 \mathrm{~s}$ during the 5 min recording. The number of feeding strikes per period of $30 \mathrm{~s}$ was also recorded. The rate of decline in the counted Artemia was used as an index of prey capture ability. The number of Artemia captured per feeding strike was used as an index of prey capture efficiency.

\subsection{Body length and ethoxyresorufin-O-deethylase activity}

At the end of the behavioral tests, body length was measured in all living larvae using a stereo microscope equipped with an ocular micrometer. Fifteen unfed larvae per treatment were then frozen in liquid nitrogen and stored at $-80^{\circ} \mathrm{C}$ for ethoxyresorufin- $O$-deethylase (EROD) analyses. Ethoxyresorufin- $O$-deethylase activity was measured in the S9 fraction prepared from homogenates of 5 whole mummichog larvae, at $22^{\circ} \mathrm{C}$ by a microplate spectrofluorometric assay (Fragoso et al., 1998) using a Cytofluor II ${ }^{\circledR}$ plate reader (excitation $530 \mathrm{~nm}$, emission $590 \mathrm{~nm}$, Perseptive Biosystems, Framinghan, MA, USA) and 96-wells microplates. Reaction mixtures contained $50 \mu 1$ S9 in N-2hydroxyethylpiperazine-N'-2-ethanesulfonic acid (HEPES) buffer (0.1 M pH 7.8), $10 \mu$ nicotinamide adenine dinucleotide phosphate (NADPH, $20 \mathrm{mg} / \mathrm{ml})$ and $50 \mu \mathrm{l}$ of 7 -ethoxyresorufin $(0.024 \mathrm{mg} / \mathrm{ml})$ in DMSO. Activity was quantified by measuring the fluorescence of resorufin at 60 -s intervals over a total scan time of $13 \mathrm{~min}$. Fluorescence readings were compared to a resorufin standard curve. All samples were assayed in triplicate. Total protein content of the S9 fractions was measured with Bradford reagent using bovine serum albumin as standard (BIO-RAD Laboratories, Hercules, CA, USA). EROD activity was expressed as pmoles resorufin $\mathrm{min}^{-1} \mathrm{mg}^{-1}$ protein. 


\subsection{Effect of post-hatching development}

One possible mechanism by which toxic chemicals can alter behavior of larval fish is by causing retardation in development. Marine fish larvae hatch with relatively undeveloped sensory and locomotor systems and they acquire progressively greater capacities as their development progresses (Fuiman and Magurran, 1994). To compare changes induced by PCB126 with changes that could come from retarded development, body length $(\mathrm{N}=48)$, spontaneous locomotor capacity $(\mathrm{N}=48)$, prey capture ability $(\mathrm{N}=$ 6), and EROD activity ( $\mathrm{N}=3$ pools of 5 larvae) were also measured in untreated Fundulus larvae collected at $0.5,1,2,3$ and $4 \mathrm{dph}$. The larvae were kept unfed at $22.5^{\circ} \mathrm{C}$ and under fluorescent light and natural photoperiod, with daily water renewal.

\subsection{Statistical analyses}

Body length, EROD activity, percentage of inactivity, active swimming speed, rate of travel, percentage of Artemia remaining after $4.5 \mathrm{~min}$, number of feeding strikes in $4.5 \mathrm{~min}$ and number of Artemia captured per feeding strikes were not normally distributed and were compared among treatments with a Kruskal-Wallis test $(\mathrm{KW})$. When significant differences were detected $(\mathrm{p} \leq 0.05)$, it was followed by a one-way ANOVA on a ranked data set with Tukey's studentized range test (Conover, 1980). The $4.5 \mathrm{~min}$ time point was used instead of the $5 \mathrm{~min}$ time point because for one out of the 8 microplates, the video camera was accidentally stopped $30 \mathrm{sec}$ too early. The linear relationships between number of Artemia in the wells and time (Log-transformed) were assessed by least-square regression for each larva. The slopes of these relationships were compared among treatments using KW. The relationships between prey capture ability and EROD activity as well as between the number of Artemia captured and the number of feeding strikes were also examined using least square regression.

\section{Results}

\subsection{Effect of PCB126}


Exposure to PCB126 caused a significant reduction in body length (5\%) at the highest topical dose, 50 pg PCB126 $\mathrm{egg}^{-1}(\mathrm{KW}, p<0.0001)$ (Fig. 1A). Treatment of the egg with PCB126 caused a doseresponsive induction of EROD activity $(\mathrm{KW}, p=0.009)$. The lowest observed effective topical dose (LOED) was $6.3 \mathrm{pg}$ PCB126 $\mathrm{egg}^{-1}$ (Fig. 1B). At the highest dose, EROD activity was 8-times higher than control. No mortality, malformation or delayed hatching was observed. Survival was $100 \%$ in all treatments and controls.

Treatment of the eggs with PCB126 did not cause a significant change in the \% of inactivity of the larvae (KW, $p=0.059)$. However, at the highest dose the larvae tended to be more inactive (Fig. 2A). At the highest dose, the larvae had a higher active swimming speed compared to DMSO controls $(\mathrm{KW}, p=$ 0.03; Fig. 2B). The rate of travel was not affected by PCB126 (KW, $p=0.85$; Fig. 2C).

Treatment of the eggs with PCB126 caused a dose-responsive reduction in prey-capture ability (KW,

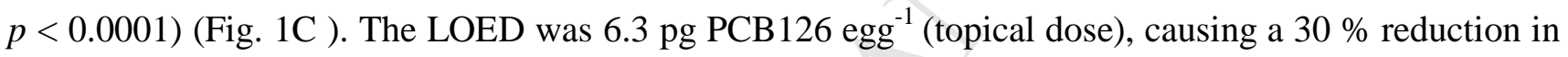
the percentage of Artemia captured after $4.5 \mathrm{~min}$. At the highest dose tested, the larvae captured almost no Artemia. The Artemia were eaten at a steadily declining rate (Fig. 3A). The slopes of the relationships between the number of Artemia remaining in the wells and time (logarithmically transformed) differed significantly among treatments (Table 1), with a significant decline in the rate of capture at doses greater or equal to $6.3 \mathrm{pg} \mathrm{egg}^{-1}$ (Fig. 3A). The number of feeding strikes did not differ significantly among treatments (KW, $p=0.088$; Table 1). Prey capture efficiency (number of Artemia captured per feeding

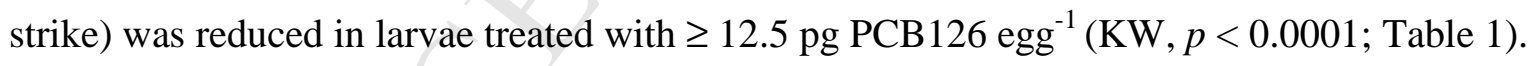

Prey capture ability decreased as EROD activity increased $\left(\mathrm{R}^{2}=0.85\right)$. The number of Artemia captured could not be predicted from the number of feeding strikes in larvae treated with topical doses ranging from 3.1 to $50 \mathrm{pg}$ PCB126 $\mathrm{egg}^{-1}\left(\mathrm{R}^{2}=0.05, \mathrm{p}=0.15, \mathrm{~N}=40\right.$, Fig. 4A). However, if the highest dose is removed from the analysis, the number of Artemia captured can be predicted with low accuracy from the number of feeding strikes $\left(3.1-25 \mathrm{pg}\right.$ PCB126 $\left.\mathrm{egg}^{-1} ; \mathrm{R}^{2}=0.17, \mathrm{p}=0.02, \mathrm{~N}=32\right)$. The coefficient of determination is further improved if only the two lowest doses are considered (3.1-6.3 pg PCB126 $\mathrm{egg}^{-1} ; \mathrm{R}^{2}=0.57, \mathrm{p}=0.0007, \mathrm{~N}=16$ ). This was associated with the fact that several larvae 
treated with $\geq 12.5 \mathrm{pg}$ PCB126 $\mathrm{egg}^{-1}$ captured less Artemia than expected from their number of feeding strikes. In particular, three larvae in the highest dose group captured $\leq 3$ Artemia despite attempting $\geq 25$ feeding strikes (Fig. 4A).

\subsection{Effect of post-hatching development}

Immediately after hatching $(\mathrm{dph}=0.5)$, the larvae had a slightly shorter body length $(5 \%)$ compared to later in the development (KW, $p<0.0001)$ (Fig. 1D). Basal EROD activity was low in the first 4 days post-hatching $\left(<1\right.$ pmol. $\mathrm{min}^{-1} \cdot \mathrm{mg}^{-1}$ protein). EROD activity was slightly lower on $4 \mathrm{dph}$ compared to $0.5 \mathrm{dph}(\mathrm{KW}, p=0.03$, Fig. 1E). No mortality occurred in unexposed larvae.

Post-hatching development significantly affected the spontaneous locomotor activity of the larvae. On 0.5 and $1 \mathrm{dph}$, the \% of inactivity was higher than later in the development (KW, $p<0.0001$; Fig. 2D). The active swimming speed and the rate of travel were lowest on $1 \mathrm{dph}$ and highest on $2 \mathrm{dph}(\mathrm{KW}, p<$ 0.0001; Fig. 2E and 2F).

Post-hatching development also affected the capacity of the larvae to capture prey (KW, $p=0.0004)$. On $0.5 \mathrm{dph}$, the larvae captured almost no prey whereas on 3 and 4 dph they captured almost all Artemia (Fig. 1F). The slopes of the relationships between the number of Artemia remaining in the wells and time (logarithmically transformed) differed significantly among treatments (KW, $p=0.001)$. As larval development progressed, the Artemia were eaten at a steadily increasing rate (Table 1 and Fig. 3B).

At $0.5 \mathrm{dph}$, nearly no feeding strikes were observed (Fig. 4B). The number of feeding strikes was lower on $2 \mathrm{dph}$ compared to 1 and $3 \mathrm{dph}(\mathrm{KW}, p=0.0006$; Table 1$)$. The prey capture efficiency (number of Artemia captured per feeding strike) was reduced on 1 and 2 dph compared to 3 and 4 dph $(\mathrm{KW}, p=0.0002$; Table 1). The number of Artemia captured could be predicted from the number of feeding strikes in untreated developing larvae $\left(R^{2}=0.71, p \leq 0.0001, N=29\right.$, Fig. 4B).

\section{Discussion}

\subsection{Effect of post-hatching development in unexposed larvae}


Fundulus larvae hatch at a relatively advanced stage of development compared to other marine fish larvae. On hatching day, they have pigmented eyes, an opened mouth, a yolk sac partially absorbed and some swimming ability (Armstrong and Child, 1965). The ability of unexposed Fundulus larvae to capture live prey (number of Artemia captured per unit of time) increased markedly from 0.5 to $4 \mathrm{dph}$. These results are consistent with a previous study showing improved captured ability in Fundulus from 3 to $14 \mathrm{dph}$ (Zhou et al., 2001). On 0.5 and $1 \mathrm{dph}$, the larvae spent more time resting compared to later in their development. Swimming activity has a direct influence on prey encounter rates and therefore on prey capture (Zhou et al., 2001). The number of feeding strikes was lower at 0.5 and $2 \mathrm{dph}$ compared to 3-4 dph and the prey capture efficiency (number of Artemia captured per feeding strike) increased as development progressed. This is likely a consequence of post-hatching development of eyes, chemosensory organs, as shown in other fish species (Yufera and Darias, 2007).

The larvae were shorter on the day of hatching compared to 1 to $4 \mathrm{dph}$. Absorption of the yolk sac during this time period could change the larval conformation making them more elongated, and also contribute to some growth (Armstrong and Child, 1965). Basal whole body EROD activity was low as expected in control larvae not exposed to inducing chemicals.

\subsection{Effect of PCB126}

Previous studies have described morphological abnormalities typical of exposure to dioxin-like compounds in the embryos of various fish species, including Fundulus heteroclitus, treated with PCB126 (Nacci et al., 1998;Foekema et al., 2008;Na et al., 2009). As far as we are aware this is the first study to demonstrate that behavioral alterations occur in early life stages of fish exposed to a coplanar PCB, at doses causing no morphological abnormalities.

Altered capture ability was reported in rainbow trout (Oncorhynchus mykiss) larvae treated with

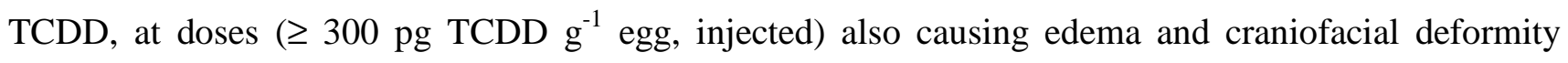
(Carvalho and Tillitt, 2004). In this study, altered prey capture ability was observed at topical doses (6.350 pg TCDD-TEQs $\mathrm{g}^{-1} \mathrm{egg}$ ) causing no mortality or obvious deformity. Alterations of body length or of 
spontaneous locomotor activity were only observed at the highest dose (50 pg PCB126 egg $\left.{ }^{-1}\right)$. Contrary to observations made in less-developed unexposed larvae (0.5-1 dph), the PCB126-exposed larvae had an increased active swimming speed and no change in their rate of travel. Hyperactivity following perinatal exposure to $\mathrm{PCB} 126$, or to other coplanar or ortho-PCBs, has been reported in mice and rats (Eriksson and Fredriksson, 1998;Kuriyama and Chahoud, 2004;Vitalone et al., 2008). At lower topical doses of PCB126 (6.3 to 25 pg PCB126 egg $^{-1}$ ), the capacity of larvae to capture live preys was reduced without detectable alterations in their spontaneous locomotor activity. In contrast, in unexposed lessdeveloped larvae, the reduction in prey capture ability was always associated with alteration in spontaneous activity, indicative of immature motor development.

In rainbow trout, impaired vision related to CYP1A induction, vascular damage, and reduction in retinal ganglion cells density has been proposed as one possible mechanism leading to reduced prey capture ability (Carvalho and Tillitt, 2004). In our study, several larvae exposed to $\geq 12.5$ pg PCB126 $\mathrm{egg}^{-1}$ captured a small number of Artemia despite numerous feeding strikes whereas in untreated developing larvae, the number of Artemia captured was highly correlated to the number of feeding strikes. These PCB126-treated larvae were missing their preys as if they were not seeing them adequately or if they lacked coordination. In untreated less-developed larvae, lower prey capture ability was strongly related to lower number of feeding strikes indicating that these larvae have a lower ability to detect prey or to initiate feeding strikes in response to prey. In contrast, several larvae exposed to PCB126 were able to detect the prey and to initiate feeding strikes in response to prey but their feeding strikes were unsuccessful. Thus, other mechanisms than retarded development appear to be involved in the reduction in prey capture efficiency in PCB126-treated larvae. Our observations are consistent with a toxicity-induced visual motor impairment, as previously described in trout exposed to TCDD (Carvalho and Tillitt, 2004).

In PCB126-treated larvae, prey capture ability was highly correlated to EROD activity. Co-planar PCBs cause uncoupling of CYP1A and consequently generation of reactive oxygen species and oxidative stress in fish (Schlezinger et al., 2006). Vitamin E, an antioxidant, protected zebrafish 
embryos against PCB126-induced toxicity (edema and growth retardation) (Na et al., 2009). Apoptosis and CYP1A induction have been observed in the brain and eyes of Fundulus embryos exposed to relatively high doses of TCDD, also causing mortalities and malformations (Toomey et al., 2001). High induction of CYP1A in the brain has also recently been demonstrated in adult male Fundulus injected intraperitoneally with $10 \mu \mathrm{g}$ PCB126 kg $\mathrm{kg}^{-1}$ (Zanette et al., 2009). However, the direct role of CYP1A in TCDD embryotoxicity is controversial in zebrafish with two studies using morpholinos to block CYP1A induction giving contradictory results (Teraoka et al., 2003; Carney et al., 2004). Unfortunately, this powerful technique has not been used to investigate the role of CYP1A induction in the embryotoxicity of TCDD in other fish species than zebrafish or in any fish species exposed to a coplanar PCB. The AhR signaling pathways are complex and several genes are likely involved in the variety of toxic responses induced by dioxin-like compounds (Antkiewicz et al., 2006;Jonsson et al., 2007). Thus, further mechanistic studies are required to demonstrate a direct role of CYP1A induction in PCB126-induced developmental neurotoxicity in larval fish.

The LOED for EROD induction was $6.3 \mathrm{pg}$ PCB126 $\mathrm{egg}^{-1}$ (topical dose) which is equivalent to 6.3 pg TCDD-TEQs $\mathrm{g}^{-1} \mathrm{egg}$, using an egg mass of $5 \mathrm{mg}$ and a toxic equivalent factor $(\mathrm{TEF}=0.005)$ derived from early life-stage mortality studies in rainbow trout (Zabel et al., 1995). EROD activity is known to be one of the most sensitive responses to dioxin-like chemicals (Cook et al., 2003). Based on immunohistochemical staining, CYP1A induction occurred in lake trout sac fry at an injected dose of 22 pg TCDD g ${ }^{-1}$ egg but not at a dose of $11 \mathrm{pg} \mathrm{g}^{-1}$ egg (Guiney et al., 1997). Thus, early life stages of Fundulus appear very sensitive to CYP1A induction by PCB126 compared to lake trout. However, the TEF of 0.005 for PCB126 was estimated from data on rainbow trout early life stage mortality (Zabel et al., 1995) and may not be appropriate for sublethal responses in Fundulus. Toxic equivalent factors may differ between embryolethality and other responses such as EROD induction, and among different fish species (Harris et al., 1993).

Topical treatment was used for this study. Using this method, it was possible to deliver quickly and non-invasively a reliable dose of PCB126 on the chorion of each individual egg. In a previous study 
(Couillard et al., 2008), we have determined that the PCB126 concentration in larvae originating from eggs treated topically with $0.1 \mu \mathrm{l}$ of a $100 \mathrm{pg}$ PCB126 $\mu \mathrm{l}^{-1}$ was $710 \pm 97 \mathrm{pg} \mathrm{g}^{-1}$ wet weight (mean \pm standard deviation). The average uptake ( \pm standard deviation) topically applied PCB126 was thus $21 \pm$ $5 \%$ in the larva, based on a larval mass of $2.9 \pm 0.4 \mathrm{mg}$. There was a linear relationship between the degree of EROD activity measured in larva and the topical dose applied to the chorion, indicating that the percent uptake was similar among different topical doses of PCB126. Moreover, we have repeated the experiment once and found no significant difference in the dose-EROD activity relationships between experiments (ANCOVA, $\mathrm{p} \leq 0.05$, unpublished data).

\subsection{Environmental relevance}

The LOEDs for both EROD induction and prey capture ability were $6.3 \mathrm{pg}$ TCDD-TEQs $\mathrm{g}^{-1}$ wet weight egg (topical doses). The effective dose, absorbed in the tissues of the larvae, is less than $25 \%$ of the nominal dose applied on the eggshell (see discussion above). This dose is environmentally relevant. For example, concentrations in lake trout eggs varied between 11 to $45 \mathrm{pg}$ TCDD-TEQs $\mathrm{g}^{-1}$ in Lake Ontario, ON, Canada, from 1978 to 1991 (Cook et al., 2003). It is possible that our results underestimate the toxicity of dioxin-like compounds in feral eggs contaminated by maternal transfer. Exposure of the mother could affect nutrients transfer into the eggs in addition to contaminant transfer (Doyon et al., 1999). Interactions between dioxin-like compounds and other contaminants are also possible (Nakayama et al., 2005).

The onset of exogenous feeding is a critical stage of development in larvae, and it has been associated with massive mortalities both in wild and cultured populations (Yufera and Darias, 2007). Impacts of contaminants on the capacity of fish larvae to capture live preys can lead to population changes of the predators, their preys, or both (Weis et al., 2001). Larval fish individual-based models are being increasingly used to relate behavioral effects of contaminants to population-relevant indices (growth and survival) (Murphy et al., 2008). 
This study has shown that environmentally realistic exposure to PCB126 causes behavioural alterations in Fundulus larvae similar to those previously described in trout exposed to TCDD. Thus, low doses of planar halogenated hydrocarbons could interact additively to cause impaired prey capture ability in fish larvae. Further research, based on the results of this study, will lead to the development of toxic equivalent factors for this low-dose ecologically relevant response for various fish species. This information will be used to assess the possible contribution of exposure to sublethal doses of dioxin-like compounds to the impaired recruitment observed in several fish species such as the American eel (Anguilla rostrata).

\section{Acknowledgements}

This project was funded by a Canadian National Research Council Strategic Grant (STPGP 350862 07). We thank P.V. Hodson for the leadership of the project.

\section{References}

Alvarez, M.C. and Fuiman, L.A., 2005. Environmental levels of atrazine and its degradation products impair survival skills and growth of red drum larvae. Aquatic Toxicology 74, 229-241.

Antkiewicz, D.S., Peterson, R.E., and Heideman, W., 2006. Blocking expression of AHR2 and ARNT1 in zebrafish larvae protects against cardiac toxicity of 2,3,7,8-tetrachlorodibenzo- $p$-dioxin. Toxicological Sciences 94, 175-182.

Armstrong, P.B. and Child, J.S., 1965. Stage in the normal development of Fundulus heteroclitus. Biological Bulletin 128, 143-169.

Boyd, J.F. and Simmonds, R.C., 1974. Continuous laboratory production of fertile Fundulus heteroclitus (Walbaum) eggs lacking chorionic fibrils. Journal of Fish Biology 6, 389-394. 
Cantrell, S.M., Joy-Sclezinger, J., Stegeman, J.J., Tillitt, D.E., and Hannink, M., 1998. Correlation of 2,3,7,8-tetrachlorodibenzo- $p$-dioxin-induced apoptotic cell death in the embryonic vasculature with embryotoxicity. Toxicology and Applied Pharmacology 148, 24-34.

Carney, S.A., Peterson, R.E., and Heideman, W., 2004. 2,3,7,8-Tetrachlorodibenzo-p-dioxin activation of the aryl hydrocarbon receptor/aryl hydrocarbon receptor nuclear translocator pathway causes developmental toxicity through a CYP1A-independent mechanism in zebrafish. Molecular Pharmacology 66, 512-521.

Carvalho, P.S. and Tillitt, D.E., 2004. 2,3,7,8-TCDD effects on visual structure and function in swim-up rainbow trout. Environmental Science and Technology 38, 6300-6306.

Conover, W.J., 1980. Practical nonparametric statistics, 2nd ed.John Wiley \& Sons, New York, NY, US. Cook, P.M., Robbins, J.A., Endicott, D.D., Lodge, K.B., Guiney, P.D., Walker, M.K., Zabel, E.W., and Peterson, R.E., 2003. Effects of aryl hydrocarbon receptor-mediated early life stage toxicity on lake trout populations in Lake Ontario during the 20th century. Environmental Science and Technology 37, 38643877.

Couillard, C.M., Lebeuf, M., Legare, B., and Trottier, S., 2008. Effects of diazinon on mummichog (Fundulus heteroclitus) larvae produced from eggs differentially treated with PCB126. Archives of Environmental Contamination and Toxicology 54, 283-291.

Dong, W., Teraoka, H., Kondo, S., and Hiraga, T., 2001. 2, 3, 7, 8-tetrachlorodibenzo-p-dioxin induces apoptosis in the dorsal midbrain of zebrafish embryos by activation of arylhydrocarbon receptor. Neuroscience Letters 303, 169-172.

Dong, W., Teraoka, H., Tsujimoto, Y., Stegeman, J.J., and Hiraga, T., 2004. Role of aryl hydrocarbon receptor in mesencephalic circulation failure and apoptosis in zebrafish embryos exposed to $2,3,7,8$ tetrachlorodibenzo-p-dioxin. Toxicological Sciences 77, 109-116.

Dong, W., Teraoka, H., Yamazaki, K., Tsukiyama, S., Imani, S., Imagawa, T., Stegeman, J.J., Peterson, R.E., and Hiraga, T., 2002. 2,3,7,8-tetrachlorodibenzo-p-dioxin toxicity in the zebrafish embryo: local 
circulation failure in the dorsal midbrain is associated with increased apoptosis. Toxicological Sciences 69, 191-201.

Doyon, C., Fortin, R., and Spear, P.A., 1999. Retinoic acid hydroxylation and teratogenesis in lake sturgeon (Acipenser fulvescens) from the St. Lawrence River and Abitibi region, Quebec. Canadian Journal of Fisheries and Aquatic Sciences 56, 1428-1436.

Emran, F., Rihel, J., and Dowling, J.E., 2008. A behavioral assay to measure responsiveness of zebrafish to changes in light intensities. Journal of Visualized Experiments 20.

Eriksson, P. and Fredriksson, A., 1998. Neurotoxic effects in adult mice neonatally exposed to 3,3'4,4'5pentachlorobiphenyl or 2,3,3'4,4'-pentachlorobiphenyl. Changes in brain nicotinic receptors and behaviour. Environmental Toxicology and Pharmacology 5, 17-27.

Foekema, E.M., Deerenberg, C.M., and Murk, A.J., 2008. Prolonged ELS test with the marine flatfish sole (Solea solea) shows delayed toxic effects of previous exposure to PCB 126. Aquatic Toxicology 90, 197-203.

Fragoso, N.M., Parrott, J.L., Hahn, M.E., and Hodson, P.V., 1998. Chronic retene exposure causes sustained induction of CYP1A activity and protein in rainbow trout (Oncorhynchus mykiss). Environmental Toxicology and Chemistry 17, 2347-2353.

Fuiman, L.A. and Magurran, A.E., 1994. Development of predator defenses in fishes. Reviews in Fish Biology and Fisheries 4, 145-183.

Gahtan, E., Tanger, P., and Baier, H., 2005. Visual prey capture in larval zebrafish is controlled by identified reticulospinal neurons downstream of the tectum. Journal of Neuroscience 25, 9294-9303.

Guiney, P.D., Smolowitz, R.M., Peterson, R.E., and Stegeman, J.J., 1997. Correlation of 2,3,7,8tetrachlorodibenzo- $p$-dioxin induction of cytochrome P4501A in vascular endothelium with toxicity in early life stages of lake trout. Toxicology and Applied Pharmacology 143, 256-273.

Harris, M., Zacharewski, T., and Safe, S., 1993. Comparative potencies of Aroclors 1232, 1242, 1248, 1254, and 1260 in male Wistar rats--assessment of the toxic equivalency factor (TEF) approach for polychlorinated biphenyls (PCBs). Fundamental and Applied Toxicology 20, 456-463. 
Hays, S.M. and Aylward, L.L., 2003. Dioxin risks in perspective: past, present, and future. Regulatory Toxicology and Pharmacology 37, 202-217.

Helder, T., 1981. Effects of 2,3,7,8-tetrachlorodibenzo-p-dioxin (TCDD) on early life stages of rainbow trout (Salmo gairdneri, Richardson). Toxicology 19, 101-112.

Helmstetter, M.F. and Alden, R.W., 1995. Passive trans-chorionic transport of toxicants in topically treated Japanese medaka (Oryzias latipes) eggs. Aquatic Toxicology 32, 1-13.

Jonsson, M.E., Jenny, M.J., Woodin, B.R., Hahn, M.E., and Stegeman, J.J., 2007. Role of AHR2 in the expression of novel cytochrome P450 1 family genes, cell cycle genes, and morphological defects in developing zebra fish exposed to 3,3',4,4',5-pentachlorobiphenyl or 2,3,7,8-tetrachlorodibenzo-p-dioxin. Toxicological Sciences 100, 180-193.

Kuriyama, S.N. and Chahoud, I., 2004. In utero exposure to low-dose 2,3',4,4',5-pentachlorobiphenyl (PCB 118) impairs male fertility and alters neurobehavior in rat offspring. Toxicology 202, 185-197.

Murphy, C.A., Rose, K.A., Alvarez, M.C., and Fuiman, L.A., 2008. Modeling larval fish behavior: scaling the sublethal effects of methylmercury to population-relevant endpoints. Aquatic Toxicology 86, 470484.

Na, Y.R., Seok, S.H., Baek, M.W., Lee, H.Y., Kim, D.J., Park, S.H., Lee, H.K., and Park, J.H., $2009 b$. Protective effects of vitamin E against 3,3',4,4',5-pentachlorobiphenyl (PCB126) induced toxicity in zebrafish embryos. Ecotoxicology and Environmental Safety 72, 714-719.

Nacci, D., Coiro, L., Kuhn, A., Champlin, D., Munns, W., Specker, J., and Cooper, K., 1998.

Nondestrcutive indicator of ethoxyresorufin- $O$-deethylase activity in embryonic fish. Environmental Toxicology and Chemistry 17, 2481-2486.

Nakayama, K., Oshima, Y., Nagafuchi, K., Hano, T., Shimasaki, Y., and Honjo, T., 2005. Early-life-stage toxicity in offspring from exposed parent medaka, Oryzias latipes, to mixtures of tributyltin and polychlorinated biphenyls. Environmental Toxicology and Chemistry 24, 591-596. 
Piedrafita, B., Erceg, S., Cauli, O., Monfort, P., and Felipo, V., 2008. Developmental exposure to polychlorinated biphenyls PCB153 or PCB126 impairs learning ability in young but not in adult rats. European Journal of Neuroscience 27, 177-182.

Schlezinger, J.J., Struntz, W.D., Goldstone, J.V., and Stegeman, J.J., 2006. Uncoupling of cytochrome P450 1A and stimulation of reactive oxygen species production by co-planar polychlorinated biphenyl congeners. Aquatic Toxicology 77, 422-432.

Teraoka, H., Dong, W., Tsujimoto, Y., Iwasa, H., Endoh, D., Ueno, N., Stegeman, J.J., Peterson, R.E., and Hiraga, T., 2003. Induction of cytochrome P450 1A is required for circulation failure and edema by 2,3,7,8-tetrachlorodibenzo-p-dioxin in zebrafish. Biochemical and Biophysical Research Communication 304, 223-228.

Tillitt, D.E. and Papoulias, D.M., 2002. 2,3,7,8-Tetrachlorodibenzo-p-dioxin toxicity in the zebrafish embryo: local circulation failure in the dorsal midbrain is associated with increased apoptosis. Toxicological Sciences 69, 1-2.

Toomey, B.H., Bello, S., Hahn, M.E., Cantrell, S., Wright, P., Tillitt, D.E., and Di Giulio, R.T., 2001. 2,3,7,8-Tetrachlorodibenzo- $p$-dioxin induces apoptotic cell death and cytochrome P4501A expression in developing Fundulus heteroclitus embryos. Aquatic Toxicology 53, 127-138.

Vitalone, A., Catalani, A., Chiodi, V., Cinque, C., Fattori, V., Goldoni, M., Matteucci, P., Poli, D., Zuena, A.R., and Costa, L.G., 2008. Neurobehavioral assessment of rats exposed to low doses of PCB126 and methyl mercury during development. Environmental Toxicology and Pharmacology 25, 103-113.

Walker, M.K. and Peterson, R.E., 1991. Toxic equivalency factors for polychlorinated dibenzo- $p$-dioxins (PCDDs), dibenzofurans (PCDFs), and biphenyls (PCBs) based on rainbow trout early life stage mortality. Abstract P094. Society of Environmental Toxicology and Chemistry. 12th Annual Meeting. November 3-7, 1991, Seattle, Washington, p. 162.

Weis, J.S., Samson, J., Zhou, T., Skurnick, J., and Weis, P., 2003. Evaluating prey capture by larval mummichogs (Fundulus heteroclitus) as a potential biomarker for contaminants. Marine Environmental Research 55, 27-38. 


\section{ACCEPTED MANUSCRIPT}

Weis, J.S., Smith, G., Zhou, T., Santiago-Bass, C., and Weis, P., 2001. Effects of contaminants on behavior: Biochemical mechanisms and ecological consequences. Bioscience 51, 209-217.

Yufera, M. and Darias, M.J., 2007. The onset of exogenous feeding in marine fish larvae. Aquaculture 268, 53-63.

Zabel, E.W., Cook, P.M., and Peterson, R.E., 1995. Toxic equivalency factors of polychlorinated dibenzo$p$-dioxin, dibenzofuran and biphenyl congeners based on early stage mortality in rainbow trout (Oncorhynchus mykiss). Aquatic Toxicology 31, 315-328.

Zanette, J., Jenny, M.J., Goldstone, J.V., Woodin, B.R., Watka, L.A., Bainy, A.C., and Stegeman, J.J., 2009. New cytochrome P450 1B1, 1C2 and 1D1 genes in the killifish Fundulus heteroclitus: Basal expression and response of five killifish CYP1s to the AHR agonist PCB126. Aquatic Toxicology 93, 234-243.

Zhou, T., Scali, R., and Weis, J.S., 2001b. Effects of methylmercury on ontogeny of prey capture ability and growth in three populations of larval Fundulus heteroclitus. Archives of Environmental Contamination and Toxicology 41, 47-54. 


\section{Figure captions}

Figure 1. Effect of treatment of eggs with 3,3',4,4',5 pentachlorobiphenyl (PCB126) (Fig. 1A, 1B,1C) or of post-hatching development (Fig. 1D,1E,1F) on body length, ethoxyresorufin- $O$-deethylase (EROD) activity and prey capture ability of Fundulus larvae. Larvae treated with PCB126 were examined on the fourth day post-hatching (dph). Values are expressed as medians (bars), first and third quartiles (triangles). Different letters indicate significant differences among doses of PCB126 or post-hatching days $(\mathrm{p} \leq 0.05)$. Sample sizes are indicated on each figure.

Figure 2. Effect of treatment of eggs with 3,3',4,4',5 pentachlorobiphenyl (PCB126) (Fig. 2A, 2B, 2C) or of post-hatching development (Fig. 2D, 2E, 2F) on spontaneous locomotor activity of Fundulus larvae. Larvae treated with PCB126 were examined on the fourth day post-hatching (dph). Values are expressed as medians (bars), first and third quartiles (triangles). Different letters indicate significant differences among doses of PCB126 or post-hatching days $(\mathrm{p} \leq 0.05) . \mathrm{N}=10($ Fig.2A, 2B, 2C) or $\mathrm{N}=$ 48 (Fig. 2D, 2E, 2F).

Figure 3. Effect of treatment of eggs with 3,3',4,4',5 pentachlorobiphenyl (PCB126) (Fig. 3A) or of post-hatching development (Fig. 3B) on the rate of capture of Artemia by mummichog larvae. Larvae treated with PCB126 were examined on the fourth day post-hatching (dph). The slopes of the relationships between the numbers of Artemia remaining in the wells and time (logarithmically transformed) were compared among doses of PCB126 or post-hatching days (Table 1). Different letters indicate significantly different slopes among treatments $(\mathrm{p} \leq 0.05)$. $\mathrm{N}=8$ (Fig. 3A) or $\mathrm{N}=6$ (Fig. 3B).

Figure 4. Relationship between the number of Artemia captured and the number of feeding strikes in 4 day post-hatching (dph) Fundulus larvae treated with PCB126 (Fig.4A) or in untreated larvae sampled at 
different stages of post hatching development ( 0.5 to $4 \mathrm{dph}$ ) (Fig. 4B). The number of Artemia captured was linearly related to the number of feeding strikes in untreated developing larvae but not in PCB126 larvae. An ellipse is drawn around three points representing larvae treated with 50 pg PCB126 egg-1 capturing very few Artemia despite numerous feeding strikes. A regression line (full line) and $95 \%$ prediction intervals (dotted lines) are presented for untreated developing larvae (Fig. 4B). The 0.5 dph data was excluded from the regression analysis since $0.5 \mathrm{dph}$ larvae captured no Artemia. 


\section{Table 1}

Effect of treatment of eggs with $3,3^{\prime}, 4,4^{\prime}, 5$ pentachlorobiphenyl (PCB126) or of post-hatching development on prey capture ability and efficiency in Fundulus larvae.

\begin{tabular}{cccc}
\hline Site & $\begin{array}{c}\text { Rate of capture of Artemia } \\
(\text { Slope })^{a, b}\end{array}$ & $\begin{array}{c}\text { Number of feeding } \\
\text { strikes (in 4.5 min })^{b}\end{array}$ & $\begin{array}{c}\text { Number of Artemia } \\
\text { captured per } \\
\text { feeding strike }\end{array}$ \\
\hline Topical dose of PCB126 $\left(\mathrm{pg} \mathrm{egg}^{-1}\right), N=8^{d}$ & & \\
0.0 & $-4.63(-5.00-4.15) \mathrm{C}$ & $22(2025) \mathrm{A}$ & $0.8(0.70 .9) \mathrm{B}$ \\
3.1 & $-4.76(-5.24-3.90) \mathrm{C}$ & $17(1618) \mathrm{A}$ & $1.0(1.01 .1) \mathrm{A}$ \\
6.3 & $-3.54(-4.38-2.92) \mathrm{B}$ & $17(1118) \mathrm{A}$ & $0.9(0.61 .0) \mathrm{B}$ \\
12.5 & $-3.17(-3.63-2.73) \mathrm{B}$ & $18(1524) \mathrm{A}$ & $0.6(0.50 .7) \mathrm{C}$ \\
25.0 & $-3.32(-3.61-3.09) \mathrm{B}$ & $25(1927) \mathrm{A}$ & $0.6(0.40 .7) \mathrm{C}$ \\
50.0 & $-0.25(-0.65-0.00) \mathrm{A}$ & $9(829) \mathrm{A}$ & $0.0(0.00 .1) \mathrm{D}$ \\
Post-hatching day, $N=6$ & & $0(00) \mathrm{C}$ & $0.0(0.00 .0) \mathrm{C}$ \\
0.5 & $0.00(0.00-0.00) \mathrm{A}$ & $22(1926) \mathrm{A}$ & $0.5(0.50 .5) \mathrm{B}$ \\
1 & $-2.61(-3.16-2.49) \mathrm{B}$ & $14(817) \mathrm{B}$ & $0.5(0.50 .6) \mathrm{B}$ \\
2 & $-2.64(-2.74-1.08) \mathrm{B}$ & $22(2123) \mathrm{A}$ & $0.7(0.70 .9) \mathrm{A}$ \\
3 & $-4.87(-4.96-4.74) \mathrm{C}$ & $18(1521) \mathrm{AB}$ & $0.9(0.90 .9) \mathrm{A}$ \\
\hline
\end{tabular}

${ }^{a}$ The rate of capture is expressed as the slope of the relationships between the numbers of Artemia remaining in the wells and time (logarithmically transformed) and is used as an index of prey capture ability;

${ }^{b}$ Values are presented as medians (first third quartiles); different capital letters indicate significant differences $(\mathrm{p} \leq 0.05)$;

${ }^{c}$ The number of Artemia captured per feeding strike is used as an index of prey capture efficiency;

${ }^{d}$ Larvae treated with PCB126 were examined on the fourth day post-hatching. 
- This is the first study reporting neurobehavioural effects of PCB126 in larval fish.

- Prey capture ability of Fundulus larvae is reduced at doses causing no morphological changes.

- Prey capture ability is negatively correlated to EROD induction

- The potency of other dioxin-like compounds to induce this response should be assessed 
PCB126 in 4 dph larvae
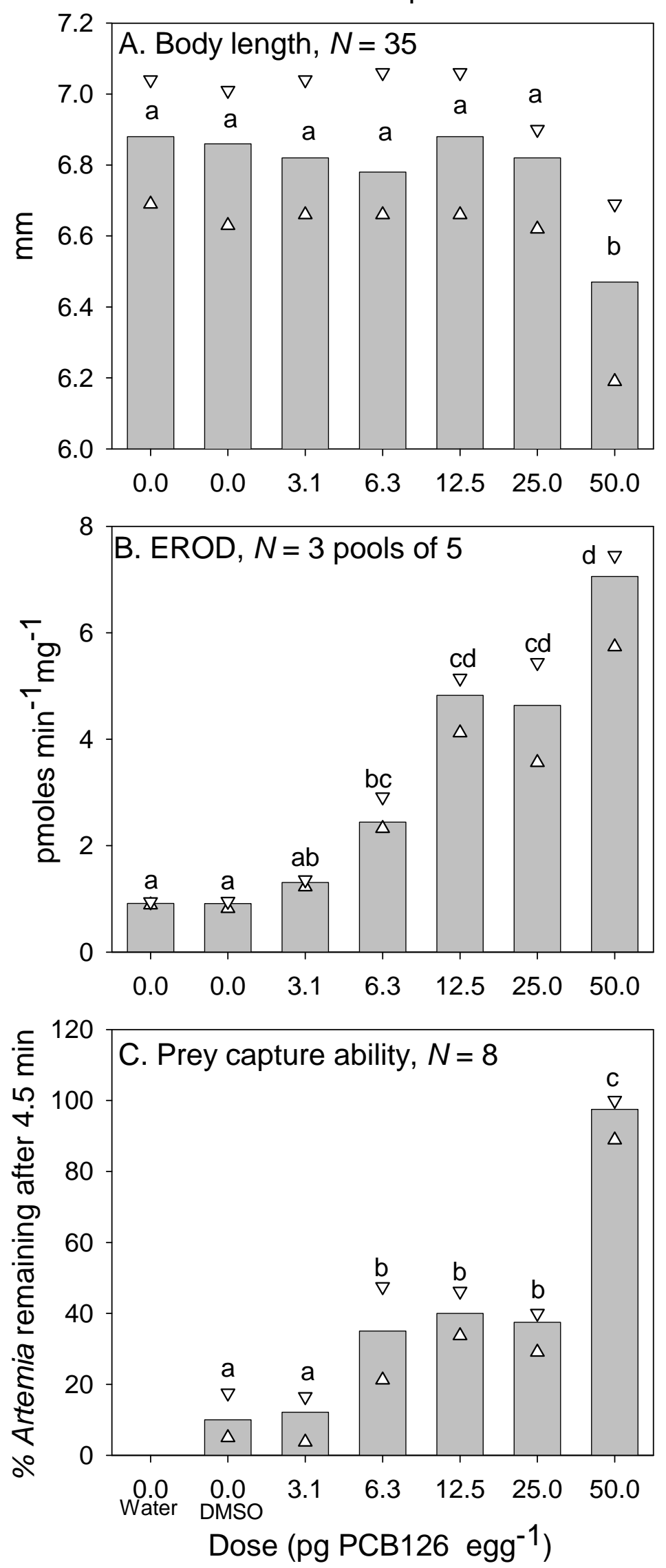

Post-hatching development
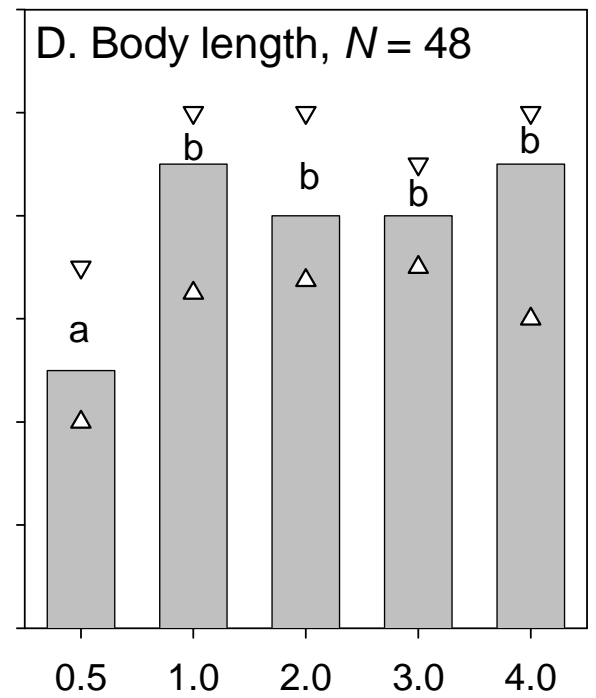

E. EROD, $N=3$ pools of 5

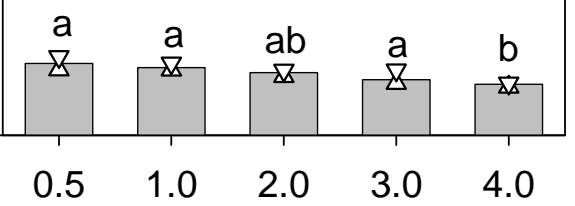

F. Prey capture ability, $N=6$

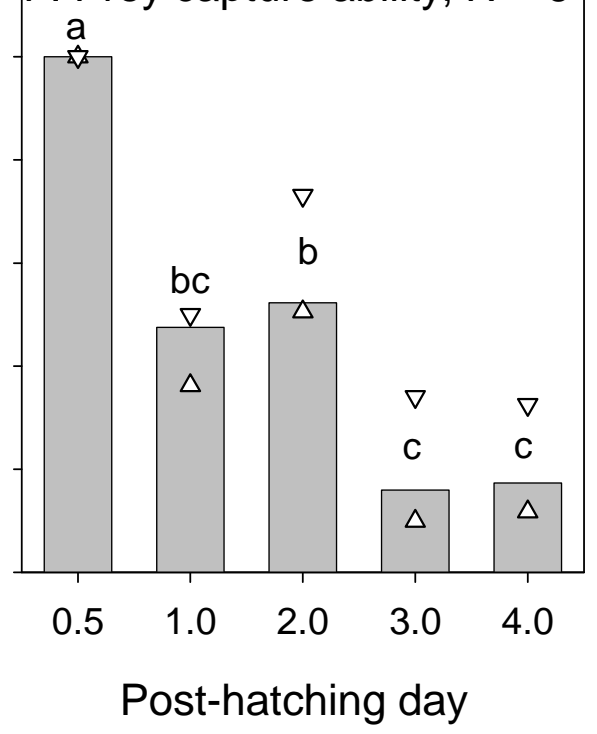


PCB126 in 4 dph larvae
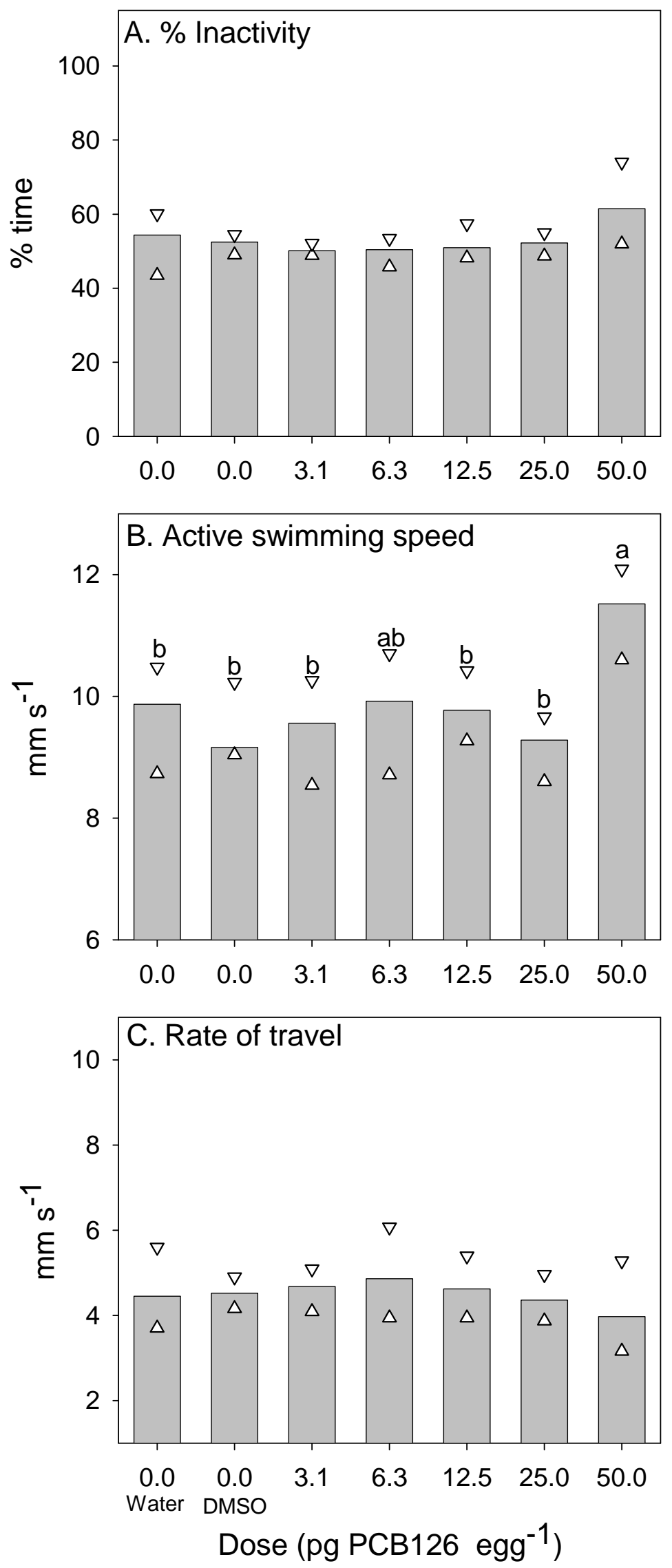

Post-hatching development

D. \% Inactivity

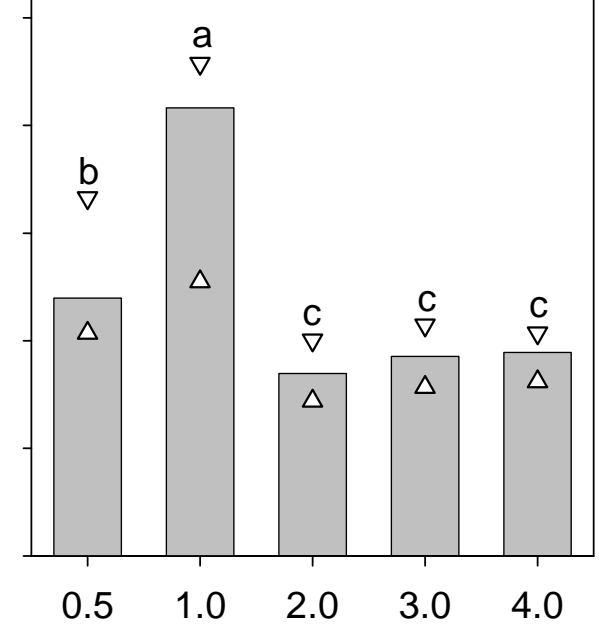

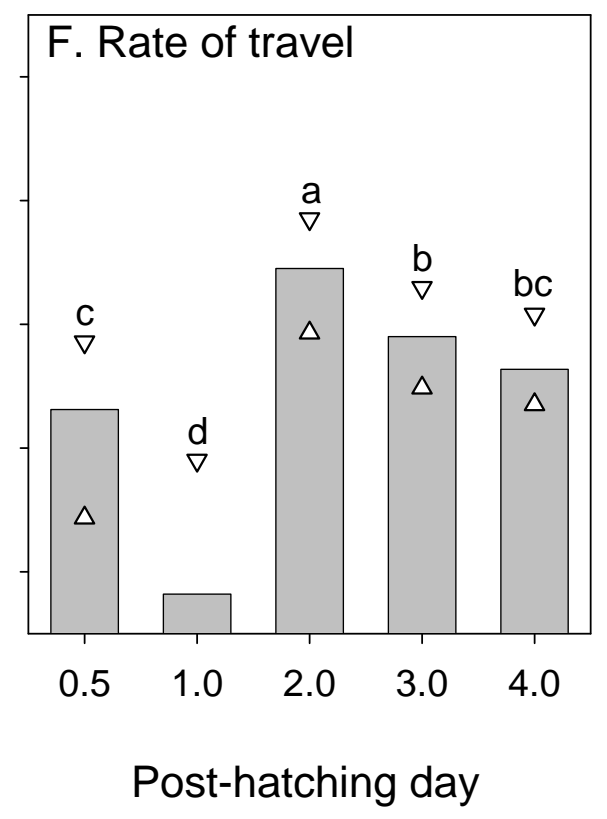




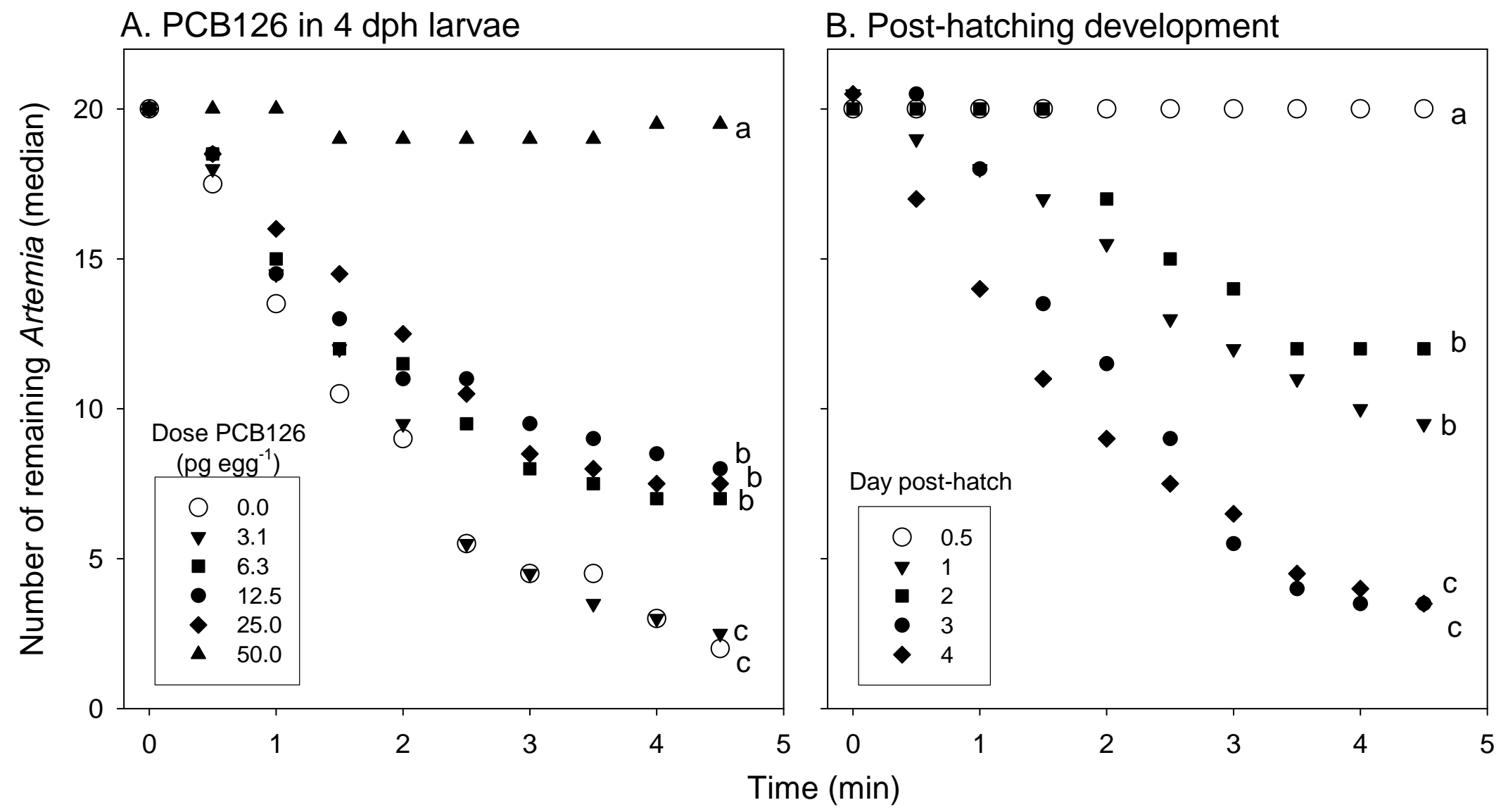




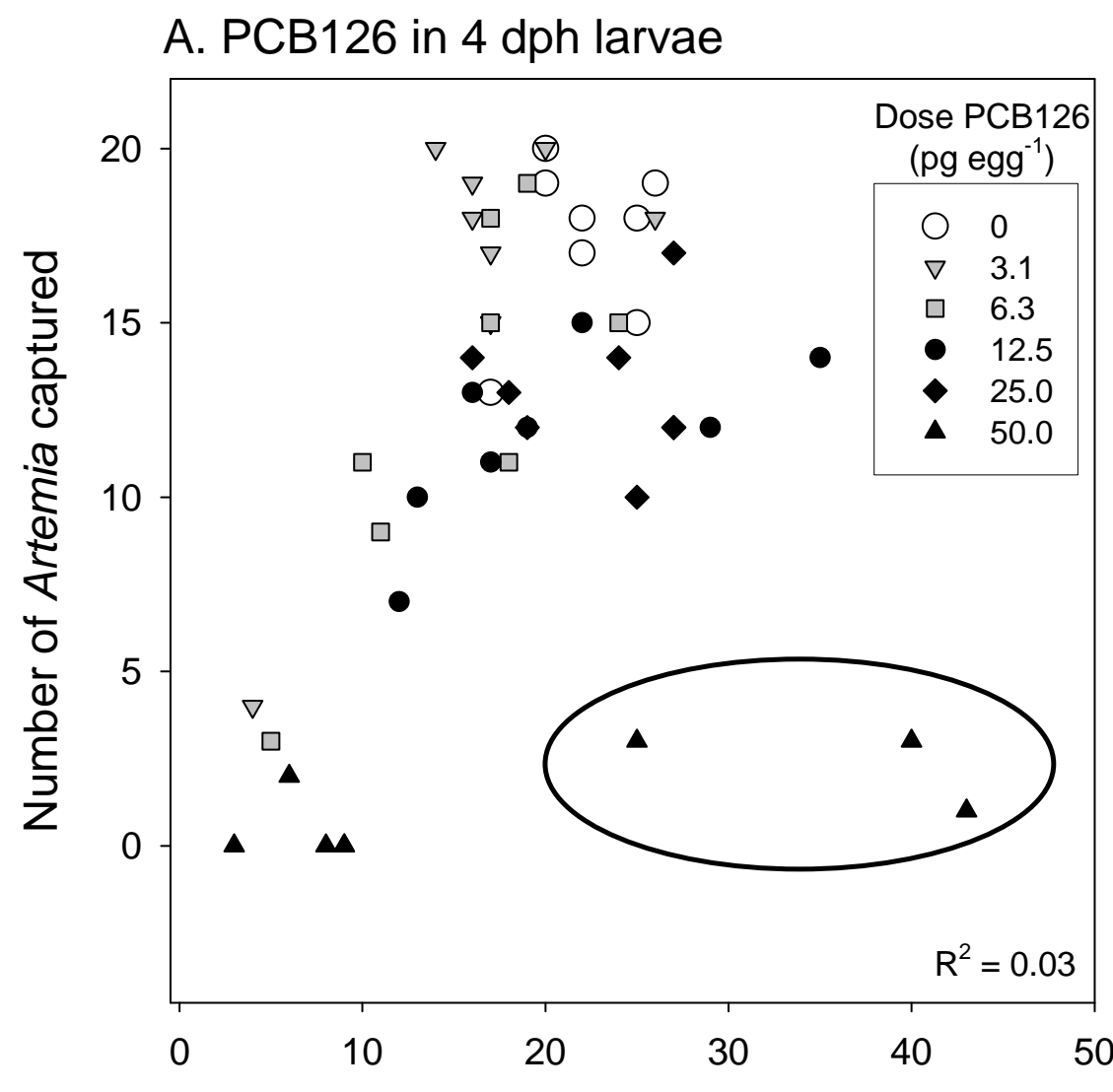

B. Post-hatching development

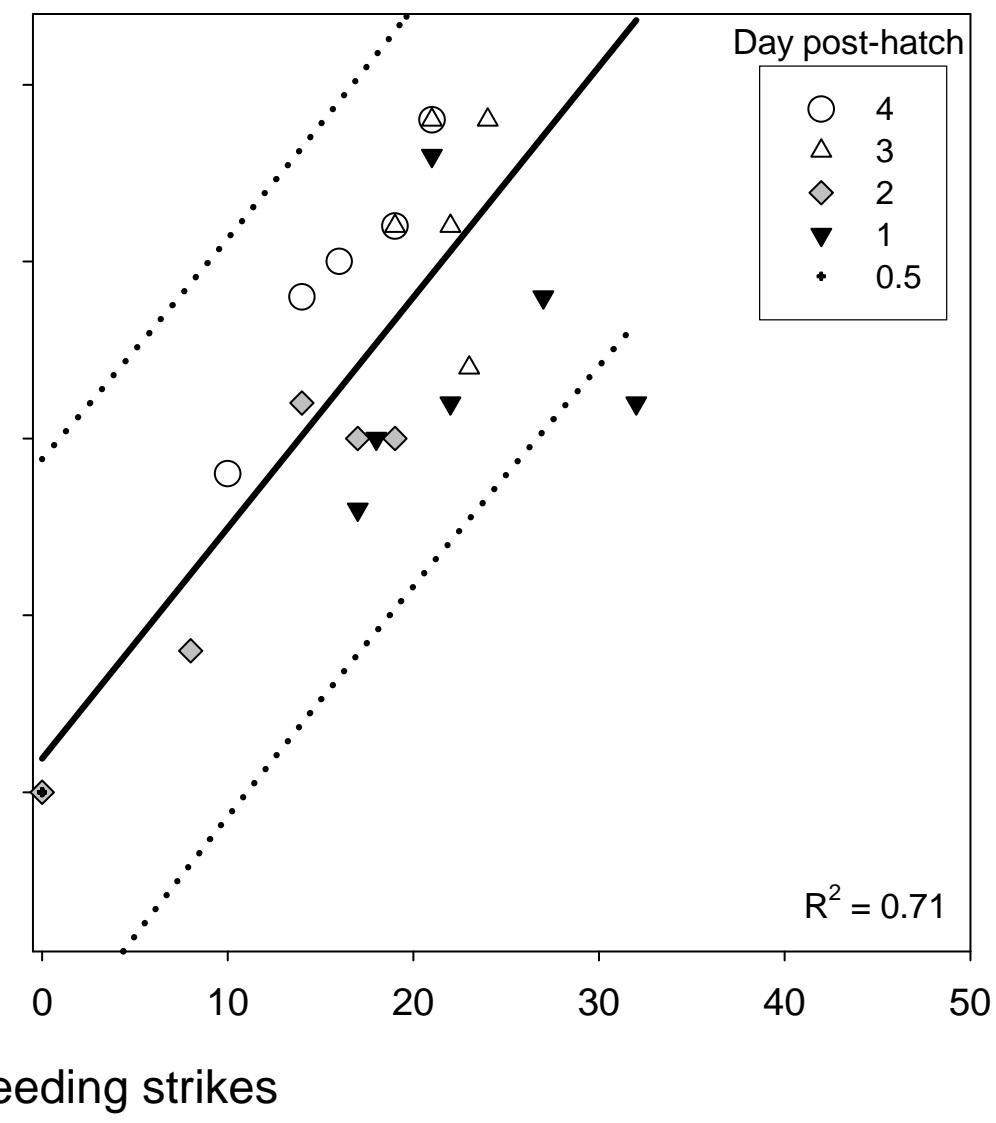

